\title{
Correlation Analysis of Hypercalcemia in Patients Treated with Total Parenteral Nutrition
}

\author{
Lin Lin $^{1}$, Fasheng Luo ${ }^{1}$, Amiya Bhaumik ${ }^{1} \&$ Divya Midhun Chakkaravarthy ${ }^{1}$ \\ ${ }^{1}$ Department of Health Sciences, Lincoln University College, Selangor Darul Ehsan, Malaysia \\ Correspondence: Lin Lin, Department of Health Sciences, Lincoln University College, Selangor Darul Ehsan, \\ Malaysia. Tel: 86-152-215-53469.
}

Received: September 15, 2020

Accepted: November 12, 2020 Online Published: November 17, 2020

doi:10.5539/gjhs.v12n13p146

URL: https://doi.org/10.5539/gjhs.v12n13p146

\begin{abstract}
Total parenteral nutrition treatment is very important for maintain patient's life, but it is complex to understand the correlation between the medical treatment and hypercalcemia. This paper explored the incidence and correlation of hypercalcemia in patients receiving total parenteral nutrition and its related factors. 280 representative patients were selected from one hospital in Guangdong Province, China, as the research objects. Collect the patient's basic attributes, nutritional status before total parenteral nutrition and total parenteral nutrition with the method of medical history retrospective, and use multiple logistic regression to explore important correlations that affect the occurrence of hypercalcemia in hospitalized patients receiving total parenteral nutrition factor. The results showed the percentage of patients with treatment days greater than 14 days that developed hypercalcemia was $7.5 \%$ which is significantly related to the occurrence of hypercalcemia. The probability of hypercalcemia in patients with total parenteral nutrition treatment for more than 14 days is higher than that of patients with treatment for less than or equal to 14 days. This study can prevent potentially harmful complications that may be caused by total parenteral nutrition and provide safer health quality.
\end{abstract}

Keywords: total parenteral nutrition, hypercalcemia, multiple logistic regression analysis

\section{Introduction}

Many hospitalized patients are unable to ingest food through the mouth or get enough nutrients through the intesTPNe to maintain the body's metabolic needs. These patients with poor gastrointesTPNal tract function will die if they do not have nutritional support. Many studies have pointed out that the prevalence of malnutrition in hospitalized patients is about 20 to $50 \%$, and malnutrition has been proven to increase the risk of complications, infections, hospitalization days, medical expenses, and death in hospitalized patients (Chang et al., 2018; Correia \& Campos, 2000; Thomas et al., 2002). Total parenteral nutrition (TPN) treatment has become one of the most important medical treatments to maintain life and it is a complex treatment method.

When the patient cannot get enough water and nutrients through the oral or intesTPNal route when the nutritional needs of the body, via glucose, amino acid, lipids, electrolytes, vitamins and trace elements into the body to provide the required physical (Agawu et al., 2019; Dudrick \& Palesty, 2011; Koss \& Joshi, 2003; Vinnars \& Wilmore, 2003). Total parenteral nutrition also potentially has serious and harmful complications, including central venous catheter-related blood stream infection, fluid and electrolyte imbalance, hyperglycemia, refeeding syndrome and metabolic bone disease. Hypercalcemia is a seldom discussed topic. Severe hypercalcemia may affect the central nervous system or cardiovascular function abnormalities and even death. Therefore, it is very important to prevent and avoid the occurrence of hypercalcemia related to total parenteral nutrition therapy in order to reduce the mortality and morbidity caused by hypercalcemia (Häusler \& Weber, 2019; Häusler, Torke, \& Weber, 2020).

In general, intravenous nutrition is through the infusion of nutrient solution through a peripheral vein. This method has been used for a long time and is easy to operate. However, hypertonic solution cannot be injected from the peripheral vein, so it cannot meet the nutritional needs of patients. Total parenteral nutrition is a deep vein infusion of high nutrient solution, which can meet the needs of patients with high nutrition. In 1962, the clinical application of this method was successful. However, this method requires certain equipment conditions, the operation technology is difficult, the aseptic operation requirements are strict, and it is prone to concurrent infection and comorbidities, so the indications must be strictly controlled. This paper mainly focused on inpatients who received 
total parenteral nutrition as the research object to explore the risk of hypercalcemia and its related factors.

\section{Method}

In this study, based on the relevant literature, the basic attributes of patients, nutritional status indicators and total parenteral nutrition therapy were analyzed by multiple logistic regression analysis to explore the main factors of hypercalcemia in patients receiving total parenteral nutrition treatment. In this study, 280 representative patients were selected from 1450 patients in ZD Hospital in Guangdong Province, China, as the research objects and data sources. The admission conditions were as follows: 320 patients over 18 years old and all patients receiving total parenteral nutrition treatment; 12 patients with hypercalcemia before total parenteral nutrition treatment and 28 patients without detection of serum calcium ion after total parenteral nutrition treatment were excluded. A total of 280 patients were included after screening. Basic data of patients were collected and filed, including gender, age, diabetes, hypertension, heart disease, hemodialysis, cancer, disease severity. Nutritional indicators include body mass index, prealbumin, albumin, blood calcium concentration and phosphorus concentration before total parenteral nutrition treatment; and total calories provided by total parenteral nutrition, days of total parenteral nutrition treatment, calcium and phosphorus dose provided by total parenteral nutrition.

The retrospective medical records to collect data, and gradually entered into the computer coding, adopted by SAS for statistical analysis statistical software, in order to ensure the correctness of the input, randomly selected $20 \%$ of the sample data matching is correct. The statistical test significance level $\alpha$ value is set to 0.05 . Statistical methods used included descriptive statistics, chi-square test and multiple logistic regression analysis. 280 subjects were selected in this paper.

\section{Results and Discussion}

The statistical data of patients' basic attributes were analyzed in Table 1 . The average age of the patients was $75.3 \pm 15.2$ years old. Most of them were older than 68 years old, $168(60 \%)$ were older than 68 years old, and 112 (40\%) were younger than 68 years old. Gender distribution was mainly male, 146 (52\%) male and 134 (48\%) female. The average total calorie of total parenteral nutrition was $908.5 \pm 163 \mathrm{kcal} / \mathrm{day}$. The distribution of TPN was less than $1000 \mathrm{kcal} /$ day in 209 patients $(74.6 \%)$ and greater than $1000 \mathrm{kcal} /$ day in $71(25.4 \%) .14 .83 \%$ of the patients received total parenteral nutrition. The average total intravenous calcium dose was $8.6 \pm 3.1 \mathrm{mEq} / \mathrm{day} .207$ patients $(73.9 \%)$ were less than $10 \mathrm{mEq} /$ day, and $73(26.1 \%)$ were greater than $10 \mathrm{mEq} / \mathrm{day} .5 \mathrm{mEq} / \mathrm{day}, 156$ $(55.7 \%)$ were less than $10 \mathrm{mEq} /$ day, and $124(44.3 \%)$ were greater than $10 \mathrm{mEq} /$ day.

Table 1. Patients basic properties analysis $(\mathrm{n}=280)$

\begin{tabular}{|c|c|c|c|c|}
\hline Variable & Number ( person ) & Percentage (\%) & The average (Mean) & Standard deviation (SD) \\
\hline \multicolumn{5}{|l|}{ Age } \\
\hline$<65$ years old & 112 & 40 & 75.3 & 15.2 \\
\hline$\geqq 65$ years old & 168 & 60 & & \\
\hline \multicolumn{5}{|l|}{ Gender } \\
\hline Female & 134 & 48 & & \\
\hline male & 146 & 52 & & \\
\hline \multicolumn{5}{|l|}{ Total parenteral nutrition therapy } \\
\hline \multicolumn{5}{|l|}{ Total energy (kcal/day) } \\
\hline$\leqq 1000$ & 209 & 76.4 & & \\
\hline$>1000$ & 71 & 25.4 & & \\
\hline TPN days & & & 16.3 & 18 \\
\hline$\leqq 14$ days & 45 & 16.1 & & \\
\hline$>14$ days & 235 & 83.9 & & \\
\hline Calcium ion dose (mEq/day) & & & 8.6 & 3.1 \\
\hline$\leqq 10$ & 207 & 73.9 & & \\
\hline$>10$ & 73 & 26.1 & & \\
\hline
\end{tabular}


Phosphorus ion dose (mmol/day)

10.3

6.5

$\begin{array}{lll}\leqq 10 & 156 & 55.7 \\ >10 & 124 & 44.3\end{array}$

The total number of patients receiving total parenteral nutrition therapy was 280 eligible for admission. Among them, 23 patients had hypercalcemia. The incidence of hypercalcemia was $8.2 \%$. Analysis of the correlation between the basic attributes of patients and the occurrence of hypercalcemia, the results showed that in terms of age, the percentage of patients younger than 65 years of age with hypercalcemia was $3.7 \%$; the percentage of patients older than 65 years of age developing hypercalcemia was $4.8 \%, \chi^{2}=0.19, p<0.48$, which is not statistically significant, and age is not associated with the occurrence of hypercalcemia. In terms of gender, the percentage of women with hypercalcemia was $3.7 \%$; the percentage of men with hypercalcemia was $4.9 \%, \chi^{2}=$ $0.22, \mathrm{p}<0.64$. It is not statistically significant, and gender is not associated with the occurrence of hypercalcemia.

The analysis of the correlation between total parenteral nutrition and the occurrence of hypercalcemia. The results in terms of total calories of total parenteral nutrition, the percentage of patients with total calories less than 1000 $\mathrm{kcal} /$ day had hypercalcemia was $6 \%$; the percentage of patients with greater than $1000 \mathrm{kcal} /$ day had hypercalcemia was $2.9 \%, \chi^{2}=1.36, \mathrm{p}<0.24$, which is not statistically significant, and total calories are not associated with the occurrence of hypercalcemia.

In terms of calcium ion dose, the percentage of patients with a dose less than $10 \mathrm{mEq} /$ day that developed hypercalcemia was $6.9 \%$ and the percentage of patients with a dose greater than $10 \mathrm{mEq} /$ day was $1.7 \%, \chi^{2}=0.29$, $\mathrm{p}<0.59$, which is not reach a statistically significant level, and calcium ion dose was not associated with the occurrence of hypercalcemia.

In terms of phosphorus ion dose, the percentage of patients with a dose of less than $10 \mathrm{mEq} /$ day who developed hypercalcemia was $5.4 \%$ and the percentage of patients with a dose greater than $10 \mathrm{mEq} / \mathrm{day}$ was $3.1 \%, \chi^{2}=0.77$, $\mathrm{p}<0.38$, which is not reach the statistically significant level, and the blood phosphorus ion concentration was not associated with the occurrence of hypercalcemia.

However, in terms of total parenteral nutrition treatment days, treatment days greater than 14 days reached a statistically significant level. The percentage of patients with treatment days greater than 14 days that developed hypercalcemia was $7.5 \%$, compared with the percentage of patients treated for less than 14 days $3.2 \%, \chi^{2}=16.83$, $\mathrm{p}<0.0001$, and the number of days of total parenteral nutrition treatment greater than 14 days is significantly related to the occurrence of hypercalcemia.

Table 2. Comparison of hypercalcemia group and non-hypercalcemia group after receiving total parenteral nutrition $(\mathrm{n}=280)$

\begin{tabular}{|c|c|c|c|c|}
\hline \multirow{2}{*}{ Variable } & \multirow{2}{*}{ Hypercalcemia group n (\%) } & \multicolumn{3}{|c|}{ Non-hypercalcemia group } \\
\hline & & $\mathrm{n}(\%)$ & $x^{2}$ & $\mathrm{p}$ \\
\hline Number of people & $23(8.2)$ & $257(91.8)$ & & \\
\hline \multicolumn{5}{|l|}{ Age } \\
\hline$<65$ years old & $11(3.7)$ & $94(33.7)$ & 0.19 & $<0.48$ \\
\hline$\geq 65$ years old & $13(4.8)$ & $162(57.8)$ & & \\
\hline \multicolumn{5}{|l|}{ Gender } \\
\hline Female & $10(3.7)$ & $122(43.7)$ & 0.22 & $<0.64$ \\
\hline male & $14(4.9)$ & $134(47.7)$ & & \\
\hline \multicolumn{5}{|c|}{ Total parenteral nutrition therapy } \\
\hline \multicolumn{5}{|l|}{ Total energy (kcal/day) } \\
\hline$\leqq 1000$ & $17(6)$ & $194(69.3)$ & 1.50 & -0.24 \\
\hline$>1000$ & $8(2.9)$ & $61(21.8)$ & & \\
\hline
\end{tabular}




\begin{tabular}{lcccc}
\hline TPN days & & & 16.83 & $<0.0001$ \\
$\leqq 14$ days & $9(3.2)$ & $174(62.3)$ & & \\
$>14$ days & $21(7.5)$ & $76(27)$ & & \\
\hline Calcium ion dose (mEq/day) & & $193(69.1)$ & 0.29 & $<0.59$ \\
$\leqq 10$ & $19(6.9)$ & $63(22.3)$ & & \\
$>10$ & $5(1.7)$ & & 0.77 & $<0.38$ \\
\hline Phosphorus ion dose (mmol/day) & $15(5.4)$ & $141(50.3)$ & & \\
$\leqq 10$ & $9(3.1)$ & $115(41.2)$ & & \\
$>10$ & & & & \\
\hline
\end{tabular}

The purpose of this study was to explore the effect of total parenteral nutrition treatment days on the occurrence of hypercalcemia. There is no relevant research in the literature. For the observation of clinical nursing experience, most patients who need to receive total intravenous nutrition therapy for a long time are patients with poor mobility, long-term bed rest and severe illness. The results of this study may be similar to the study of Livingstone, Phillips, Davis, Marvin, and Stebbing (2004) that pointed out that bone resorption is the main cause of hypercalcemia when the patient is bedridden for a long time. The advantage of this study is that there is little literature on the influencing factors of hypercalcemia in patients receiving total parenteral nutrition. This study has three limitations. First, a single institution is prone to sample selection bias. As a result, it cannot be transferred to patients receiving total parenteral nutrition treatment in other medical institutions. A retrospective generation study was adopted to collect the basic medical records of past hospitalized patients, and the relevant physiological test values before and after total intravenous nutrition treatment. The purpose of the research is not to make causal inferences. Secondly, many related factors discussed in the literature, such as bed rest, hyperparathyroidism, and vitamin $\mathrm{D}$, are all related to hypercalcemia and cannot be discussed. If there are related studies in the future, it is recommended to list related variables among them. Furthermore, this study monitors the blood calcium ion concentration instead of serum free calcium. In the research literature of Alzahrani et al. (2013), it is recommended to monitor blood serum free calcium to avoid acute blood albumin. The decrease results in a decrease in the concentration of calcium ions bound to albumin.

\section{Conclusion}

This paper adopts a retrospective generation study to explore the factors that affect the occurrence of hypercalcemia in patients receiving total parenteral nutrition. In this study, the basic attributes of patients, nutritional status before receiving total parenteral nutrition, total parenteral nutrition treatment and nutritional status after receiving total parenteral nutrition were discussed. The results showed that age and gender were not statistically significant in the Chi-square test and logistic regression analysis, and the basic attributes of the patient such as age and gender were not associated with hypercalcemia. The incidence of hypercalcemia in patients with total intravenous nutrition treatment for more than 14 days is higher than that of patients with treatment for less than or equal to 14 days $(\mathrm{AOR}=5.013)$. The treatment days greater than 14 days are significantly related to the occurrence of hypercalcemia. Hemodialysis, body mass index and the number of days of total parenteral nutrition treatment are important factors affecting the occurrence of hypercalcemia in hospitalized patients receiving total intravenous nutrition. In addition, hypercalcemia usually occurs at the end of malignant tumors, mainly due to the increase in bone resorption, which causes a large amount of bone calcium to run into the blood, leading to hypercalcemia. Hypophosphatemia and hypercalcemia often occur blood disease. If these patients use phosphate to treat hypercalcemia, the risk of calcium phosphate (CaPO4) precipitation and deposition is significantly increased, which may lead to renal diabetes insipidus, renal vasoconstriction and intravascular calcium deposition causing prerenal nitrogen qualitative disease leads to renal failure, and severe cases require dialysis (Andreoli et al., 2010). The results of this paper can provide patients with sufficient energy and comprehensive nutrients to prevent and correct malnutrition, enhance the patient's physical fitness and tolerance to trauma, and promote the patient's speedy recovery.

\section{Competing Interests Statement}

The authors declare that there are no competing or potential conflicts of interest.

\section{References}

Agawu, A., Wehrman, A., Pogoriler, J., Terry, N. A., \& Lin, H. C. (2019). A case report of a challenging diagnosis 
of biliary atresia in a patient receiving total parenteral nutrition. BMC Pediatrics, 19(1). https://doi.org/10.1186/s12887-019-1446-2

Elhassan, A. O., Tran, L. B., Clarke, R. C., Singh, S., \& Kaye, A. D. (2017). Total parenteral and enteral nutrition in the ICU: evolving concepts. Anesthesiology Clinics, 35(2), 181-190. https://doi.org/10.1016/j.anclin.2017.01.004

Kang, M. C., Kim, J. H., Ryu, S. W., Moon, J. Y., Park, J. H., Park, J. K., ... \& Song, G. A. (2017). Prevalence of malnutrition in hospitalized patients: a multicenter cross-sectional study. Journal of Korean Medical Science, $33(2)$.

Correia, M. I. T., Campos, A. C. L., \& Study, E. C. (2003). Prevalence of hospital malnutrition in Latin America:: The multicenter ELAN study. Nutrition, 19(10), 823-825. https://doi.org/10.1016/S0899-9007(03)00168-0

Häusler, D., Torke, S., \& Weber, M. S. (2020). High-Dose Vitamin D-Mediated Hypercalcemia as a Potential Risk Factor in Central Nervous System Demyelinating Disease. Frontiers in Immunology, 11, 301. https://doi.org/10.3389/fimmu.2020.00301

Dudrick, S. J., \& Palesty, J. A. (2011). Historical highlights of the development of total parenteral nutrition. Surgical Clinics, 91(3), 693-717. https://doi.org/10.1016/j.suc.2011.02.009

Edington, J., Boorman, J., Durrant, E. R., Perkins, A., Giffin, C. V., James, R., ... \& Blackshaw, V. (2000). Prevalence of malnutrition on admission to four hospitals in England. Clinical nutrition, 19(3), 191-195. https://doi.org/10.1054/clnu.1999.0121

Elhassan, A. O., Tran, L. B., Clarke, R. C., Singh, S., \& Kaye, A. D. (2017). Total parenteral and enteral nutrition in the ICU: evolving concepts. Anesthesiology Clinics, 35(2), 181-190. https://doi.org/10.1016/j.anclin.2017.01.004

Häusler, D., \& Weber, M. S. (2019). Vitamin D Supplementation in Central Nervous System Demyelinating Disease-Enough Is Enough. International Journal of Molecular Sciences, 20(1), 218. https://doi.org/10.3390/ijms20010218

Ijaz, S. H., Mazhar, M., Bhatti, U. A., \& Tran, N. T. (2018, April). Simple Thrombus or Something More Sinister: Intracardiac Fungal Ball Secondary To Total Parenteral Nutrition; The Only Reported Case. In Journal of Investigative Medicine (Vol. 66, No. 4, pp. 868-869). British Med Assoc House, Tavistock Square, London Wc1h 9jr, England: Bmj Publishing Group.

Knoth, H., Maywald, D., \& Walter, W. (2016). In-vitro detection of mannan and galactomannan in components of total parenteral nutrition (TPN). Die Pharmazie-An International Journal of Pharmaceutical Sciences, 71(5), 238-242.

Koss, W., \& Joshi, N. (2003). Prescribing total parenteral nutrition. Nutrition, 19(9), 819-820. https://doi.org/10.1016/S0899-9007(03)00102-3

Ma, J., Gao, M., Pan, R., He, L., Zhao, L., Liu, J., \& Liu, H. (2018). Hyperglycemia is associated with cardiac complications in elderly nondiabetic patients receiving total parenteral nutrition. Medicine, 97(6). https://doi.org/10.1097/MD.0000000000009537

Mueller, M. H., Vandenbussche, K., Pelliccia, M., Smith, M., Karanicolas, P., Hanna, S., ... \& Law, C. (2015). Enteral Nutrition Support Reduces the Necessity of Total Parenteral Nutrition to Reach Patient-Specific Caloric Goals Postpancreaticoduodenectomy. Southern medical journal, 108(12), 748-753. https://doi.org/10.14423/SMJ.0000000000000385

Nunes, G., Fonseca, C., Barosa, R., Patita, M., Gomes, A., Botas, J., ... \& Fonseca, J. (2018). Idiopathic chylous ascites in a patient with HIV infection: response to total parenteral nutrition and octreotide therapy. Clinical journal of gastroenterology, 11(3), 235-239. https://doi.org/10.1007/s12328-018-0832-x

Pirlich, M., Schütz, T., Kemps, M., Luhman, N., Burmester, G. R., Baumann, G., ... \& Lochs, H. (2003). Prevalence of malnutrition in hospitalized medical patients: impact of underlying disease. Digestive diseases, 21(3), 245-251. https://doi.org/10.1159/000073342

Thomas, D. R., Zdrowski, C. D., Wilson, M. M., Conright, K. C., Lewis, C., Tariq, S., \& Morley, J. E. (2002). Malnutrition in subacute care. The American journal of clinical nutrition, 75(2), 308-313. https://doi.org/10.1093/ajen/75.2.308

Vidal, A., Arnold, N., Vartolomei, M. D., Kiss, B., Burkhard, F., Thalmann, G. N., \& Roth, B. (2016). Oncological 
and functional outcomes of postoperative total parenteral nutrition after radical cystectomy in bladder cancer patients: A single-center randomized trial. International journal of urology, 23(12), 992-999. https://doi.org/10.1111/iju.13228

Vinnars, E., \& Wilmore, D. (2003). History of parenteral nutrition. Journal of parenteral and enteral nutrition, 27(3), 225-231. https://doi.org/10.1177/0148607103027003225

Yue, S., Hong-Xia, M. A., Ling, S., \& Department, P. (2019). Effect of total parenteral nutrition and traditional chinese medicine in the treatment of severe ulcerative colitis. Clinical research and practice.

\section{Copyrights}

Copyright for this article is retained by the author(s), with first publication rights granted to the journal.

This is an open-access article distributed under the terms and conditions of the Creative Commons Attribution license (http://creativecommons.org/licenses/by/4.0/). 